no uncomfortable effect when sprayed directly into and erysipelas were called the "scourges of surgery." the tracheal wound. This treatment appeared grate- They followed the operator step and pace, defeating ful to the patient in his distress, as also did the all his efforts.

forced respiration application when it was made. In "Eighty per cent. of all wounds are complicated fact he eagerly requested that it be utilized later in by gangrene," wrote Lindpaintner from Nussbaum's the case, as it had relieved him once or twice. But, clinic, in Munich. Erysipelas was of such common of course, the difficulty was in the prevention of occurrence in association with wounds, that men formation of the exudates, which ultimately pre- came to regard it as almost a natural complication. vented the respiratory process from being carried on, It was made an established rule never to suture weakening the patient so that the heart succumbed scalp wounds, on account of fear that pus would to the strain put upon it. I think there.is no question accumulate.

from the result of the other cases that had this boy been placed in time upon the treatment to which the other children were subjected he might have recovered.

This paper is presented to this Section on account of its bearing upon an operation the surgeon must frequently perform, and if through means of this character the surgeon may be prevented from experiencing that most unenviable notoriety of losing a case during an operation it will be worth the time expended.

Healing by primary mion was almost unknown, and suturing had at most the result of causing retention and accumulation of the secretions and favoring the development of erysipelas. In one report of seventeen amputations, eleven died of pyæmia alone.

A compound fracture seldom occurred which was not either at once amputated, or else the patient died soon as the result of intercurrent gangrene, purulent infection or septicæmia.

The mortality of compound fractures in Volkmann's clinic at Halle for a number of years was 40 per cent., and during 1871 and 1872 pyæmia and erysipelas became so frequent as to necessitate the clinic

\section{ADVANCES IN ASEPTIC SURGERY.}

Read in the Section of Surgery and Anatomy, at the Forty-third Annual Meeting of the American Medical Association, held at Detroit, Mich., Juue, 1892.

BY FRANK J. THORNBURY, M.D.,

LATE SENIOR RESIDENT PHYSICIAN, CINCINYATI HOSPITAL, CINCINYATI, O.; DEMONSTRATOR OF BACTERIOLOGY, MEDICAL DEPARTMENT UNIVERSTYY OF BLFFALO.

I desire to precede the reading of this paper by the statement that much of what I have to say is the product of work recently done in the von Bergmann Clinic, at Berlin.

Many of the ideas and facts are comprised in Schimmelbusche's "Aseptische Wound Behandlung," recently published to formulate in no limited amount of original work, done by von Bergmann's corps and other German investigators.

Having been assigned the English translation of this book, I take the privilege of utilizing some of its contents in this paper, which may serve in a measure as an introduction to the translated volume, which I hope in a short time to have completed.

In considering the subject of the advances in this department of our science, it seems very appropriate to review for a moment the past state of events, that we may be better able to draw the necessary deductions and convince ourselves of the extent of the progress.

We will not go back to the time in which deficiency of anatomical and physiological learning, as well as incompetency in technique, impeded the progress of surgery-but rather refer to a later era of uncertainty in the results seemingly dependent upon some grave mysterious influence which pervaded the field of surgery, and baffled the operator's most earnest efforts.

I refer to the time when the subject of wounds and fever were inseparable; the time when healing without inflammation was unknown, and wound suppuration appeared as the natural reaction of the injured organism.

This was the time when Pirogoff wrote that "all efforts of the physician and surrounding circum. stance were of no avail, and that the results of an operation are dependent entirely upon fate."

Suppuration, purulent œedema, tetanus, gangrene

\section{being closed.}

How different it is to-day. The hospitals which twenty years ago numbered gangrene among their most frequent and disastrous complications of wounds, now never present a case for the observation of the student, and the majority of the younger surgeons scarcely know this disease.

The gravest operations now run a favorable course. "Fate" and " mishap" are terms no longer permissible. For the occurrence of suppuration the operator is directly accountable. The future of the patient rests in $h$ is hands.

We operate in youth and in the aged with the same assurance of a favorable result as that entertained in the robust adult of middle years. The abdomen and the cranium are opened without hesitation, and the visceral contents palpated or incised. We no longer believe that in a carcinomatous or tubercular patient a fresh wound is going to heal other than it would in a healthy individual. The theory of a diathesis predisposing to wound inflammation is a thing of the past.

For this enormous transition in surgical science, we are indebted to the illumination of the dark cloud suspended for so long a time over wound infectionto the revelation that in living microorganisms rests the danger. If the methods originally used were those now employed in combating the mighty enemy, then there would shine in more brilliant light the name of him who first showed us the way to progress - that of Sir John Lister.

But to Hunter belongs the original observation that subcutaneous wounds and simple fractures are unattended by suppuration; Lister comes later with the announcement that germs are the cause of infection, but claims that the infection takes place through the atmosphere. Elaborate "antiseptic" spray arrangements were accordingly for a time in vogue. Later investigations, however, proved that the air is rarely the medium of infection, that the natural habitat of organisms is organic material on the earth and elsewhere. Only as dry dust do germs get into the atmosphere. From moist surfaces they cannot arise.

The principal circumstances under which bacteria 
are found in the air are, first, in winds and other forms of violent agitation of the atmosphere; secondly, in rooms after sweeping, and in enclosed compartments with defective ventilation and bad hygenic surroundings; and finally, they are present in the air of densely populated cities.

Here we may find bacilli and micrococci, in numbers varying from a few to many thousands per cb. $\mathrm{cm}$. : while in the free open air, principally moles and the spores are present in limited numbers.

In mid-ocean atmosphere there are no germs present. Of this fact I convinced myself in a recent transatlantic voyage.

While still in the Shelda River and English Channel, and again on nearing Sandy Hook and sailing into New York Bay, occasional isolated colonies de. veloped on exposed agar plates. In mid-ocean, between 5 and 40 degrees $W$. longitude, no germs at all were present in the atmosphere. This was also true of the air blowing from the iceberged Newfoundland banks. In the staterooms and in the first and second cabins of the steamer, on the other hand, many bacteria were found on short exposures, especially in the halls after dining hours.

In the steerage, where there were 1,100 emigrants packed together in filth, many thousand bacilli and micrococci came to luxuriant development on agar plates and in the large gelatine tubes.

The colonies in 3 to 5 liter aspirations were numerable only by Esmarch's graduated scale. Many of the bacteria thus isolated presented virulent characteristics as regards grow th and development. I have made some inoculation experiments, but as these are not yet completed, I cannot now make further definite report.

The reverse of dryness, diffused daylight and sunshine, nature's anti-microbic resources, are all present in close packed compartments, like the rooms of a tenement house and the steerage, and hence the multiplicity of forms of infectious bacteria here present.

The recent incubation of a typhus fever epidemic on an emigrant steamer reaching New York quarantine, may easily be accounted for.

Naegali demonstrated theoretically, as long ago as 1870, that only through currents of air are germs taken up from their usual habitat-organic material, and that never do they rise from solutions, however rich in bacteria. In this fact we have a valuable practical suggestion as to the importance of the spray in diphtheria and other local infectious diseases, and also the aseptic efficiency of washing down the walls, spraying the atmosphere and sprinkling the floor of the clinic previous to operationa practice executed daily by Leopold.

Moist air never contains anything like the number of germs which are present in a dry moving atmosphere. This factor, second to the absence of the prolific source, organic material, accounts for there not being any germs in the sea air and in the air of mountain tops. They are held down, in the one instance by the sea water, in the other by the snow covering the mountain peaks.

As evidence of the effect which stirring up the air has on its bacterial contents, Hesse found'that the 3,000 germs to the $\mathrm{cb}$. $\mathrm{cm}$. present ordinarily in a school room, increased to 20,000 during the sessions, and to 40,000 when the pupils were marching out of the room.
Petri found the air of crowded stables to contain 30,000 bacilli and 7,400 mold spores to the $\mathrm{cb}$. $\mathrm{cm}$.

Very extensive has been the belief, both in medicine and with the laity, that the exhaled breath may convey infection.

But Tyndall demonstrated that the air expired almost never contains germs. Strauss found that in bacteria-enriched atmosphere, in hospital wards, of 600 germs inhaled, but very few were exhaled.

Cadeac and Malet conducted the expired breath of sheep, affected with anthrax and chicken-pox, through troughs $\frac{1}{4}$ to 3 meters long, having healthy animals inhale it: but notwithstanding repeated efforts, in no instance could the non-affected animals, placed at different distances along the trough, be made per inbalation to contract the disease.

The lungs do not give up germs from their moist alveolar surfaces. On the contrary, they filter out the microbes and purify the air bacteriologically, as well as with reference to carbon dioxide.

Only through the sputum or expectorated tissue particles, or through mucus secretion, can disease be communicated from the respiratory apparatus. As Strauss states, the respiratory function must tend to diminish the bacteria in an overcrowded auditorium. It may be a source of gratification to a lecturer to know that each listener brings with him a filter in the functions of his respiratory apparatus. With every breath about $500 \mathrm{cb} . \mathrm{cm}$. of air is freed of its bacteria.

The more our knowledge of bacteriology has been extended, the less have become our fears of infection taking place through the air, and relatively unimportant is such possibility as compared with the dangers of direct contact of infectious materials.

Supposing a cubic meter of air does contain 1,000 to 20,000 germs, what is this, as compared with the half million to the ch. cm. present in river water, or the million or more contained in a single drop of pus or other highly contaminated fluid?

Repeated examinations in the von Bergmann clinic have shown that the number of germs which precipitate over an area of a quarter of a decimeter in thirty minutes of time, during the clinic hour, was at most but sixty to seventy, and as for pathogenic bacteria ever being present, it was an extreme rarity. Practical experience has long since demonstrated that the air is comparatively harmless, as regards its capability of infecting wounds.

It is the infection through contact which most engages our attention. To review the wound-infecting germs, we have first of all the erysipelas streptococcus of Fehleisen; second, the Nicolarer, Rosenbach, Kitasato, anarobic, tetanus bacillus, with its numerous ptomaines, "tetanin," "tetantoxin," "hydrochlorin " and "spasmotoxin," isolated by Brieger, capable of producing typical tetanic convulsions when inoculated even in infinitely small doses. Then we have the familiar staphylococcus pyogenes aureus, citrius and albus of ordinary suppuration, furuncle, carbuncle, paronychia, phlegmon, and nearly all the cases of pyæmia.

Fourth - the frequent cause of specially severe suppurative processes-the staphylococcus pyogenes, whose form and morphological characteristics so closely simulate the Fehleisen streptococcus of erysipelas that many bacteriologists claim them to be identical, differing only in location, representing a deep-seated and especially virulent form of the same disease. 
Less frequent, as pus formers, are other cocci, for instance the micrococcus pyogenes temuis (Rosenbach )

Very common, in excessive wound secretion, is the much discussed bacillus pyocyanus, or blue pus former. Anthrax, tubercle, glanders and diphtheria bacilli have for a long time been classed with those germs whose biological relations we thoroughly well understand. The causes of most forms of peritonitis, especially the perforative, have recently been found to be dependent upon "two germs, whose habitat is the small intestine. They are the bacillus coli communis and bacterium lectis ærogenes.

We have also a special germ for septicæmia and severe necrotic processes. There remains now only one of the wound complications whose cause we have not discovered, namely: gangrene, the former scourge of hospitals and army life, but now swept out of existence; not even affording an occasional case for necessary bacteriological observation. We have in the subsidence of this disease a most brilliant triumph for aseptic surgery.

Finally, we have isolated the varied, destructive and often epidemic animal septicæmias, namely : the swine plague, wild game plague, chicken cholera, rabbit septicxmia and ferret plague, all of which present marked similarities, but differentiate themselves in the results of inoculation in the different animals.

To make practical application of the finding of germs, the first in surgical importance to us, is their presence on the surface of the body. Eberth, in 1875 , first discovered that all imaginable forms of bacteria are found in normal perspiration.

We have on the skin all the factors conducive to the development of bacteria. First, there is the uniform temperature; second, moisture afforded by the exeretion of the glands; and third, a culture medium is formed by the decomposed epidermis. The axillary space, interdigital folds and the hairy scalp, seem to be fertile soil for every possible form of microbe life. Miller found several varieties in the mouth.

We have here the, 1 , lipothrix innominata; 2 , bacillus bucallis maximus; 3 , leptothrix bucallis maximus; 4, jodoccus vaginatus; 5 , spirillum sputegnum; 6, spirochæte dentium; and four ordinary pathogenic bacteria, viz.: 1, micrococcus gingivæ pyogenes; 2 , bacterium gingivæ pyogenes ; 3 , bacillis dentatis virides; and 4, bacillus pulpæ pyogenes.

Throughout the alimentary canal, in the female genital tract to the os internum, in the male urethra, in the upper respiratory passages, in the conjunctival secretion, and in the cerumen of the auditory canal, masses of bacteria are found. With the occurrence of a slight catarrhal process, the germs at once multiply with striking rapidity and number millions in a short time.

The cleansing of the surface of the body and the removal of the promiscuous forms of bacteria, many of which are pathogenic, constitutes the first requirement in asepsis. Not merely the skin of the patient in the region to be operated upon must be cleansed, but the still more infectious source, the hands of the surgeon. This disinfection is not an easy matter. The fat and dirt filling up the pores and epidermal folds in the skin contain a substratum rich in bacteria. A transitory submersion in the strongest sublimate solution has little influence. The fluid rolls in lutions is now clearly proven. The instruments must

drops off the fat, glistening skin, without even thoroughly moistening it. In the skin and under the nails, the number of the bacteria remain practically unaltered after such a "would-be disinfection."

Of course the absolute demand for a most careful cleansing of the surface needs no further argument. The method to be used may be formulated as follows: First, washing with soap and water as hot as can be borne, for one minute. Second, rubbing and drying the surface with sterile gauze. Third, one minute application of 80 per cent alcohol. Fourth, washing with sublimate solution. Ether in addition may be used where there is an unusual amount of dirt to be removed. The razor is most valuable over parts even not especially hairy, as it removes the superficial epidermal hairs, in which the bacteria aggregate. It cannot be applied so extensively to the scalp, but even here, the area should be shavid from 3 to $5 \mathrm{~cm}$. from the margin of the wound.

An aseptic cleansing of the mucous membranes is less easily effected. Steffeek found that irrigation of the vagina with a liter solution 1 to 1,000 bichloride had not the slightest influence in reducing the number of bacteria. A stronger solution would of course be dangerous. Erosions and acute catarrh, or a general intoxication, might result from absorption. A mechanical cleansing of the rectal, vaginal and oral mucous membrane is to some extent practicable, by means of tepid sterilized water and gauze, or a physiological solution of common salt. The stomach is also permissible of free irrigation. Operations in emergency upon the intestine should be preceded by a preparatory course of catharsis.

All the articlos and materials used in the disinfection of the surfaces cutaneous and mucous, must, of course, themselves be aseptic. The alcohol, ether and turpentine oil, only by careful handling are kept free from bacteria.

Eiselsberg showed in 1887 , that soap may be very richly impregnated with microürganisms, and only that which has been boiled in the process of its manufacture should be used.

Most danger of all and the thing to which the least attention lias been given are the nail brushes, used in removing blood, pus, surface epithelium and all forms of contamination, they naturally become more or less contaminated themselves; being moist, they retain most of the albuminous matter and form a most excellent nidus for germs. Schimmelbusch and Spielhagen in repeated examinations of the nail brushes, in clinics, dissecting rooms and laboratories found in them inestimable myriads of bacteria. That the brushes therefore, merits some attention must be conceded. Brushes in the von Bergmann clinic, are dealt with in the following manner: before being used, they are first, sterilized in steam for 30 minutes; second, they are kept continually submerged in $\frac{10}{20}$ corrosive sublimate. Third, after a special contamination, they are placed in very hot and finally in boiling water. In every commode should be placed an especially constructed enamel receptacle in which the brush can be continuously submerged in corrosive sublimate. The latter will maintain asepsis by preventing the development of bacteria after the brush has been sterilized in boiling water or steam.

Next in order the instruments themselves, will engage our attention. The impracticability of disin- 
be sterilized and the choice of method lies between These, with another sterilizer for water, presently to hot air, steam and boiling water. Only the latter of be referred to, I have through the kindness of Mr. these, will we consider. Spores of many bacilli re- Wilmot Castle, of Rochester, N. Y., been able to sist hot air at $140^{\circ} \mathrm{C}$. for two hours, and steam for place here, on exhibition, and will be pleased to demforty minutes to one hour. While boiling in soda, onstrate them to the gentlemen present.

insures absolute death of even anthrax, in three minutes. A special apparatus devised by Schimmelbusch, for this method of sterilizing instruments, together with other sterilizing apparatuses, will presently be demonstrated.

The especially commendable feature about this german sterilizer, is its economy of time; and if aninstrument happens to drop during an operation, and one that cannot be well dispensed with, we are not obliged to wait for 40 minutes, while it is being sterilized. The instrument is at once thrown into the boiling soda, continually provided in the clinic by the above sterilizer, and in three to five minutes it is taken out aseptic.

Special stress should be laid upon the mechanical th cleansing of instruments, as well as all things to be rendered aseptic. Pus, blood and masses of fat, the favorite niduse's of organisms, must rigidly be dealt with, by washing with water, soap and brush, before they are put into the boiling soda. After use, they should be carefully dried with alcohol and dry sterile gauze. But with this method there is not the liability of rusting which follows dry heat and steam. Further the instruments are not corroded as with carbolic solution and sublimate. Solutions which even applied concentrated does not insure asepsis.

In the construction of the instruments, simplicity should not be lost sight of. All ornamentations and unnecessary fixings of every kind, are contra-indicated on grounds of asepsis. The one piece of steel, may enter into the formation of both the blade and handle, or the latter may be detachable. Instruments made of aluminium; lose one-ninth of their weight, by simply boiling for five minutes. Therefore this material is not to be employed.

Next of interest to us, are the dressings to be used, the first quality they should possess is the capability of rapid absorption. Second, they should not contain any bacteria. Third, they should work antiseptically in preventing decomposition of the secretions which they absorb.

Not the dressings which absorbs its maximum at once, and then becomes packed, and remains wet, but material which takes up the secretions gradually, as they are produced and dries out by evaporation, form the ideal dressing. Stcrility the second prerequisite is absolute and applies to anything which is to come in contact with pure fresh wounds. Both Schlange and Löffler, have found factory gauze and bandages to contain many germs. The necessity of sterilizing the dressings, therefore, follows as a natural consequence. Steam in this instance, is the most efficient means at our disposal:

Schimmelbusch has invented an ingenious apparatus, which may be used for the combined purpose of an instrument and dressing sterilizer. The steam which has been generated in the boiling soda, is utilized in a chamber placed above for sterilizing the dressings. This combination answers admirably the requirements of the private practitioner. But for the more extensive usage of hospitals and amphitheatres, a special sterilizer for dressings is necessary. Then the Schimmelbusch apparatus recommends itself, or the Arnold steam sterilizer may be used.

The third requirement in dressings, is an antiseptic property. The prevention of the development of germs in the secretions of the wound which serves only too well, the purpose of a culture medium, being the indication to be met. I desire here to lay special stress upon the subject of dry dressing, as it is not in accordance with the usual ideas of wound treatment, as practiced by most surgeons. The more our experimental knowledge has been extended, the firmer has been the position gained by dryness, as a condition contrary to a germ development.

There is no remedy so harmless, simple and efficacious in preventing changes in the wound secretion, as dryness occurring of itself by evaporation. Moisture is the essential dependence of bacterial life. Dryness, on the other hand, is the germ's greatest enemy. Let the most favorable nutrient of bacteria, moisture, be dispensed with and the organisms cease to grow. I, then the absorption and drying out of the blood, pus and wound secretion be provided for, and the development of germs is prevented.

We are indebted to the Esmarch school, especially to Neuber, for having placed the importance of dry dressings in their present advanced position. Schlange in the von Bergmann Clinic, demonstrated by exacted bacterical experiments, how prompt dryness works against every form of germ life. Layers of sterile, gauze wire saturated with bullion and the upper surface impregnated with the green pus bacillis, then the gauze was placed in open glass plates; and evaporation and dryness took place, and only a very scanty development of the bacteria became perceptible. A logical consequence, and one exactly in accordance with organic life development in any form. Moisture is essential to growth. Instead of leaving the plates open, others of the same series were closed and evaporation of the moisture prevented. The pus formers now proliferated with enormous rapidity and soon formed a greenish film over the entire surface of the gauze. This suggests the practical advantage of facilitating to every possible extent, evaporations of the secretions from the wound.

First, the proper dressing material must be select. ed. Secondly, the evaporation must not be interfered with, by the interlaying of impervious material as oil silk, or gutta percha tissue. The latter, are of no special advantage, they prevent the wound and dressings from drying out, cause retention of the secretions, prohibiting even perspiration from the surface and inducing in the course of a few hours, the development of offensive odors, and very non aseptic conditions.

These facts are exactly in accordance with our laboratory experience as bacteriologists. As soon as the gelatin or agar tubes lose their surface moisture by evaporation, growth of the colonies cease, and the culture is lost. Hence the necessity of our capping the tubes, to favor the development of the bacteria-a procedure analogous to the application of impervious silk over wounds.

In the dressing then, we may combine a parasiticide influence, in dryness, an agent which will not injure the tissues locally, or cause general disturbance. It is not with bullion or water that we have to deal, in a 
wound, but rather with albuminous culture material, there are the old glass and gun drainage tubes. which decidedly limits the action of chemicals. Probably the latter are the more satisfactory in the Further, evaporation of the carbolic and sublimate solutions, takes place, and combinations form reducing the effectual workings of these agents.

In sublimated gauze after a time, only an insignicant trace of the original antiseptic is to be found. The simple dry treatment of wounds, then, is the present position of surgical science, and is reinforced on all sides by logic and rational experience and results.

No oiled silk to promote retention of secretions, no chemicals to irritate the wound, no irrigation to carry germs into it, no pus. Only in two instances is anything additional to the simple dry sterile gauze needed. One is in the case of thick tenacious purulent discharge. The other is the tamponing of cavities, and the latter indication is admirably met in the iodoform dressing. Non-irritating and non-toxic (in reasonable quantity,) it prevents changes in the absorbed secretions. Notwithstanding the repeated attack made upon it, iodoform retains its place as prominently as ever as our most reliable dressing.

In the case of excessive purulent secretion, acetic acid, oxide, or chloride of zinc may be applied to the wound.

Since it has been shown, that raw cat gut is rich in bacteria, and Volkman had two cases of anthrax develop in a wound sutured with sheep ligature in which animal anthrax is common; further, by rea. son of Koch having demonstrated that antiseptics dissolved in oil, are ineffectual, we are now required by this progress in our science, to put ligatures and catguts also, through a course of sterilization.

Steam for the silk is the best method, and Schimmelbusch has given us a sterilizer consisting of a small box, containing several spools which can be placed in the steam chamber for thirty minutes, then closed and kept for use as desired. The ends of the thread protrude through openings at the side, so that raising the cover and permitting contamination is $o b$ viated.

With reference to catgut, the various methods employed are first, von Bergmann's ether sublimate and alcohol, McEwen's chromic acid, Lister's carbolic acid method, then Benkisser's Ravardin process of dehydration and deoleation, then disinfecting by hot steam.

Kocher sterilizes the catgut in juniper oil, Brunnes in Xylol. Of these various methods, that employed by von Bergmann is the one to be recommended, and may be briefly formulated as follows: First, the bottle is sterilized for three quarters of an hour in steam. Second is a process of deoleation, by placing the catgut for 24 hours in ether. Third, submersion in alcohol and sublimate of the following proportions: bichloride 10.0 , absolute alcohol 800.0 , aq. destillata 200 .

The hermetically sealod bent tubes of Fowler, containing sterilized catgut, is also an efficient means of preserving this material aseptic.

The subject of wound drainage deserves just a passing notice. Three methods are embraced in the chapter. 1. The simple opening made through the tissues. 2. The use of drainage tubes. 3. The use of materials: capable of capillary attraction. Neuber advances the theory of an absorbable material so the wound can be closed. Trendelenburg and also McEwen used chicken bones, hollowed out. Bundles of catgut is Watson Cheyne's favored method. Then greater number of instances. They permit of being sterilized in boiling soda or steam. Five minutes of the former, 15 or 20 of the latter is sufficient to render them reliably aseptic.

They are preserved aseptic in a five per cent. carbolic acid solution, occasionally renewed. For fastening the tube in place, not the ordinary safety pin, but a sterilized silk thread passed with a needle, rendered aseptic, is to be employed.

The principle of capillary attraction can be utilized best in absorbing the discharges and wound secretion by means of the hydrophiline gauze. Absorbing pledgets for use in the operation are best supplied in the same material. Of course the gauze cannot be used but once, but we should not economize in the use of the materials applied direct to the wound but rather in the external dressing. Only gauze scrupulously sterile should be applied. Sponges while apt to be a source of danger, cannot absolutely be dispensed with, especially in operations about the mouth, resections of the jaw and in laparotomies. Absorbing so freely pus, blood and all fluids contaminated or not, they are, a priori apt to retain and convey infection and permit only with difficulty of being sterilized.

Anthrax spores were found in sponges, after being 14 days submerged in carbolic acid. The ordinary organisms live for eight days. Twenty per cent. of the sponges prepared for use in the Billroth Clinic were found by Friesch to contain bacteria. The method of preparation of the sponges, employed by Schimmelbusch, consists first in washing them thoroughly in hot water, removing carefully all foreign substances. After several rinsings they are boiled for 30 minutes in 1 per cent. soda solution, then preserved in strong corrosive sublimate. Of course they must be enveloped in gauze, so that the fingers will not come in direct contact with what is to find application perhaps in the abdominal cavity. This method can be regarded as absolute. Sponges impregnated with pus and anthrax spores did not react to culture efforts after ten minutes in the boiling soda.

For a continuance of this subject in the "Septic Dangers of Hypodermic Injection, Catheterization and Irrigation of Wounds, the reader is refered to a paper by the writer under the above title published in the Medical and Surgical Times.

610 Main St., Buffalo, N. Y.

\section{THE COSMETIC SURGERY OF THE NOSE.}

Read in the Section of surgery and Anatomy, at the Forty third annual meeting of the American Medical Association held at Detroit, Mich., June, 1892 .

\section{BY JOHN B. ROBERTS, M.D,} PROFESSOR OF STRGERY IN THE PHILADELPHIA POLYCLINIC AND IN THE
WOMAN'S MEDICAL COLLEGE OF PENNSYLVANIA.

Operative surgery can do so much to relieve disfiguring nasal deformities that perhaps the topic will prove interesting for discussion at this representative meeting. The medical profession fails to fully realize that nearly all undesirable distortions of the nose can be improved or entirely corrected by cosmetic operation. It is, therefore, not astonishing that many persons remain in constant unhappiness because of the consciousness that a congenital or accidental 